\title{
ADOLESCENTS ENGAGING IN SEXUAL ACTIVITY: AN OVERVIEW
}

\author{
Amuta Arumugam ${ }^{1}$ Dr.Ganesan Shanmugavelu, $\mathbf{P h D}^{2}$
}

\author{
Dr.Sharmini Siva Vikaraman, Phd $^{3}$, Dr.M. Nadarajan Manickam,Phd ${ }^{4}$
}

\author{
Jagdave Singh Avtar Singh ${ }^{5}$, Manimaran Vadivelu ${ }^{6}$
}

\author{
Kanaisan Kanapathy ${ }^{7}$ \\ ${ }^{1}$ Certified Counsellor, Ipoh, Perak, Malaysia \\ ${ }^{2}$ Senior Lecturer, Institute of Teacher Education Ipoh Campus, Malaysia \\ ${ }^{3}$ Senior Lecturer, English Language Teaching Centre (ELTC), Malaysia \\ ${ }^{4}$ Senior Lecturer, Institute of Teacher Education Keningau Campus, Malaysia \\ ${ }^{5}$ Principal, Sierramas Secondary School, Selangor, Malaysia \\ ${ }^{6}$ Senior Lecturer, Institute Of Teacher Education Ipoh Campus, Malaysia \\ ${ }^{7}$ Lecturer, Institute of Teacher Education Ipoh Campus, Malaysia
}

Article DOI: https://doi.org/10.36713/epra8265

DOI No: 10.36713/epra8265

\begin{abstract}
The purpose of this study is to determine the prevalence of risky sexual activities among adolescents within the context of other behavioural factors that contribute to compromised health outcomes, for both sexes, those who initiated sexual activity at an early age were more likely to engage in a variety of significant risks behaviours factor. Possibility engaging in sexual activity is associated with age, low academic performance, substance abuse, violence, depression, and suicidal tendencies. The more regular occurrence of these risk factors, the higher the chances of engaging in sexual activity. The aim of various examining is to find efforts on how specific ways of conceptualizing to reduce multiple risk factors and to determine how adolescents' views on reproductive issues influence may develop sexual initiation and patterns of behaviour in sexual activity over the time.
\end{abstract}

KEYWORD: Adolescent, Healthy, Sexual Activity, Therapy, Emotional, Multiple Risk

\section{INTRODUCTION}

This study determined adolescents who have sex earlier in life are more likely to continue to be risky into young adulthood, including more sexual partners. The theoretical growth in terms of maturity and knowledge can be seen on a large scale of the adolescent population of today (Guha, 2013). Considerable adolescents had a developmental stage associated with increased risk behaviours that contribute to negative sexual health outcomes (Ramos et al. 2015). Within attitude towards sex, emphasizing the different elements of the construct change, with premarital sex, even high risk in sexual behaviour and adolescent pregnancy presents a serious social and public health problem. Perhaps, in turn puts them at more risk of unwanted outcomes of sexual activity, including unintended pregnancy or sexually transmitted diseases. It is a multi-dimension concept and includes ethical, psychological, biological and cultural dimensions. The concept of sexuality highlights the necessity sexual behaviour within the context of global adolescent development, as they are intimately interconnected. Especially pubertal changes are accompanied by cognitive development whereby the primary task of which is developing a formal operational thought process. The abstract thinking and the ability to envision potential consequence of actions and the effect of this 


\section{EPRA International Journal of Research and Development (IJRD)

action may have on others is one key aspect of this process and clearly indicate as an important development affecting the level of health risk associated with adolescent sexual behaviours. Cross study experiencing adolescents reflect deeper problems in emotional development, broadly that defined by distress and affect dysregulation sexual risk behaviour making early sexual intervention critical. The interventions with the best evidence of effectiveness are those which address multiple risk and protective factors, resilience, positive school environments and positive parent and family interactions.

The changeover stage from childhood to adulthood is a critical period in which young adolescents have the opportunity to make decisions based on their own judgments away from parental influence. The maturity growth towards adulthood for teenagers poses a wide range of risks and harmful actions that constitute a threat to their well-being. These behaviours may impact their well-being in a negative way both physically and emotionally depending on what decisions they choose to make. Sexual activity may not itself be a risky behaviour, but to young adolescents engaging in this activity may present serious consequences to their health and wellbeing. However, they obtain in making decision to have sex as a young adolescent gratifies the desires of teenagers without having in mind the repercussions that could follow. Part of sexuality development is more complex than the biological forces that initiate the sexual maturation process and the development of adolescent sexuality includes not only physical development but also cognitive, emotional, social, and moral development. Moreover, it is emphasized throughout the particular problem with respect to adolescent sexuality because poor decisions, due to a lack of cognitive and/or emotional maturity. Essentially, caregivers to discuss all aspects of sexuality amongst adolescent, especially physical growth, emotional, social, physical and moral aspects of sexuality so that teens make wise thoughtful decisions. In a straight line they ensure parents understand the process of adolescent sexual development in a better position to assist their children, including knowledge to enable caregivers to know when to intervene. This study aims to describe the natural evolution of adolescent sexuality on their sexual thoughts and questions, their sexual feelings and concerns, their sexual behaviour and choices. This may emphasize parents be cautioned to remember that every youth is unique and their teens may reach these developmental milestones at ages and still be considered "normal."

This study also observed that early sexual activity increases the likelihood to have more frequent sexual encounters (Kahn et al. 2002) and romantic partners (Sandfort et al. 2008) which possibly will negatively impact on academic achievements since these activities are time consuming. The focus aspect in "refraining from having sex as a teenager may impart important psychological and emotional benefits, in turn, lead to increased human capital accumulation" (Sabia and Rees 2009). Sexual intercourse at a young age can distract adolescents to school achievements through unintended health consequences of becoming sexually active, such as the higher risk of unplanned pregnancies, abortion, and sexually transmitted diseases (Rector et al. 2003). Beside this there are other risk behaviours associated with early sexual intercourse are substance use and greater affiliation with deviant peers, which could lead to developing minor deviance (Bingham and Crockett 1996; Rees et al. 2001). However, studies evidenced, sex differences in depression during adolescence since females experienced a larger increase in depression and a greater decline in happiness than males in response to romantic involvement (Joyner and Udry 2000). Hallfors et al. (2005) discovered female adolescence who experienced sex with multiple partners were more likely to be depressed than their counterparts who remained sexually abstinent. However, boys engaged in sexual activity with multiple partners showed no significant increase of depression. In young ages who engage in sexual intercourse and have multiple partners might undergo negative social and health changes which, in turn, may lead to reduced interest in academic achievement.

The aim of this research considered early adolescence is the most critical stage of development, a period of accelerated growth and change. The behaviour design associated with adopting in lifelong consequences, both positive and negative attitude that encounter in individual perception about sexuality. The significant effects in premarital sexual behaviour can cause various negative impacts on adolescents, either psychological, physical and social impact. The psychological effects influence and recognition such feelings of anger, fear, anxiety, depression, low selfesteem, guilt and physical effects can lead to unwanted pregnancies and abortions that lead to develop sexually transmitted diseases (STDs) among adolescents. In fact, sexually transmitted diseases can cause infertility and may increase the risk of contracting HIV / AIDS and will produce a quality generation (Sarwono, 2011), from the social point approach used in the current study. This may further allow to identify, the impacts that are being treated are ostracized, dropping out of school for pregnant female adolescents, and changing the role of mother or father, as well as the stigma of society who denounces and rejects the situation. The early adolescence opportunity, risk and a positive school environment, taking critical ways to ensuring this age 


\section{EPRA International Journal of Research and Development (IJRD)

group's learning. Whereby, the social and physical needs that met along their support and guidance from parents as one of the most significant important factors which can mould the individual in the best positive way or the least positive way. The effective information clearly emphasizes the necessary for health professionals to prevent and intervene on not only unmarried young people's sexual behaviour, but also other negative consequence (Yip et al, 2013).

Healthy Adolescent Sexual Development

It's important that anyone who works with young people has a good understanding of how adolescent develop sexually. This can help them recognise healthy sexual behaviours that are developmentally appropriate and identify if the adolescent is displaying behaviour that is inappropriate or potentially harmful. Adolescent's development and mental health are affected by various factors, including the environments they are raised in, the relationships build and the experiences they have. Their development refers to the physical, cognitive, emotional and social growth that occurs throughout a young person's life. Hence their mental health, cognitive, behavioural and social wellbeing is affected by this development, as well as a range of factors, including trauma and abuse. The journey begins much earlier in adolescent life about sexual development is part of sexuality. In fact, by the time they reach to adolescent stage, already have received many messages about sexuality (Strasburger, 2005). While some adolescents might receive accurate and comprehensive information from school, their parents, and elsewhere, others might receive less information. Many adolescents turn to other sources of information such as their peers, the internet, and the media due to absence of healthy, realistic messages about sexuality (Gruber \& Grube, 2000). Potentially adolescent strengthen without an understanding of healthy relationships, consent, boundaries, and how to engage safely in sexual behaviours. The understanding of healthy sexuality may enable prevent sexual violence by addressing gender norms and inequality, promoting healthy relationships, encouraging an understanding of boundaries and helping young people feel empowered to ask questions that seek support when they need it.

The Goals of Promoting the Knowledge and Key Skills to Healthy Sexuality.

A wide variety of experience is normal and healthy, it can also be easy to view adolescence as a time of upheaval, rather than as a time of opportunity (McNeely \& Blanchard, 2009). The objective of following information provides an understanding of adolescent sexual development that help better support on their path to becoming healthy adults. While the information provides a general guideline for each development, it is important to remember that not all adolescents experience this in the same way.

i. Make decisions that are informed and turn to trusted adults for support and guidance when needed.

ii. Understand consent and how to respectfully interact with partners, friends, and peers.

iii. Help influence their peers in a positive manner by promoting positive social norms and engaging in bystander intervention.

iv. Recognize sexual violence and seek help and support when sexual violence occurs.

v. Provide support and information to peers and others who have experienced sexual violence.

vi. Ensuring the ability to access ageappropriate, comprehensive, education, achieving, protecting, respecting and fulfilling human rights related to sexual and reproductive health.

vii. Enabling women to avoid unintended pregnancies.

viii. Focused narrowly on specific behaviors leading to these health goals, gave clear messages about these behaviours, and addressed situations that might lead to them and how to avoid them.

ix. Addressed multiple sexual psychosocial risk and protective factors affecting sexual risk behaviours (e.g., knowledge, perceived risks, values, attitudes, perceived norms and self-efficacy).

\section{Design of Hypothesis Method}

Generally, the development pursues a variety of individual, clinician, system-level policies and strategies to ensure confidentiality, preventive and accessible sexual health care and education for adolescents. Thus, adolescents continue face numerous barriers to acquiring comprehensive and accurate sexual health information. The challenge that can ultimately inform best practice interventions that promoting positive developmental outcomes in listed hypothesis.

i. Are you now or have you ever had sex with males, females, or both?

ii. The last time you had sex?

iii. How many sexual partners have you had?

iv. How old were you when you first had sex?

v. There are various forms of contraception: did you use a condom and/or birth control with your last sexual encounter?

vi. Have you ever been worried that you were (got someone) pregnant?

vii. Have you ever had a sexually transmitted infection (STI)? 


\section{EPRA International Journal of Research and Development (IJRD)

viii. Have you ever been tested for an STI and human immunodeficiency virus (HIV)?

ix. Have you ever traded money or drugs for sex?

x. Has anyone ever touched you in a way you did not want to be touched?

xi. Has anyone forced you to do something you did not want to do sexually?

xii. Have you focuses on the needs?

xiii. How models, fosters caring and supportive relationships to increase?

xiv. How to manage self-confidence, awareness and management of behaviour?

xv. How to manage positive attitudes towards assisting others?

xvi. Clear guidelines to ensure appropriate relationships with clear expectations

\section{Analyse and Interpret Data Information.}

Adolescent focused on learning about the emotional, social and physical aspects of growing up relationships, identity, reproduction, gender, human sexuality and sexual health. A primary goal of sexuality education is to equip adolescent with the knowledge, skills and values have safe, fulfilling, enjoyable relationships and to make responsible for safe choices that promote to protect their own health, safety and wellbeing. Being able to communicate, listen and negotiate with others to make informed decisions are useful life-skills that can be applied to all relationships, including intimate relationships. Effective sexuality education includes structured opportunities for adolescent to explore their attitudes and values, and to practise their decision-making, assertiveness and other life skills needed to make informed choices about their relationships and sexual lives.

There are various competing messages about relationships, sex and sexuality in the world. Sexuality education provides opportunities for students to develop media literacy skills which are essential to help adolescent understand, interpret, evaluate media messages and imagery related to sexuality, relationships and gender. However, adolescent choose to be sexually active, thus sexuality education prioritises the acquisition and/or reinforcement of values such as reciprocity, equality, responsibility and respect, which are prerequisites for healthy, safer sexual and social relationships. These emphasize adolescent recognise these relationships long before they act on their sexuality and need the skills to understand their bodies, relationships and feelings from an early age. Effective sexuality education provides adolescent with age-appropriate, culturally relevant and scientifically accurate information. Beside this issue, parent knowledge of friends and time spent in activities problems did not affect the common problem behaviour factors, but did have effects on specific behaviours. Adolescents who spent more time in organized activities had lower levels of marijuana use and academic failure. Academic failure was also less likely for individuals whose parents knew their friends. While these results make intuitive sense, it is not clear why the effects emerged towards sexual activities in specific behaviours reasons.

Based on analysis and evaluation indicates that, where parents and carers have an understanding of their adult learning is improved. Whereby, therapy session should implement a consultative process to ensure parents and carers have the opportunity to participate in discussions on both curriculum content of teaching adults and learning materials need to be modified. Communication with parents and carers assists the community to better understand the content and aims of the establishing how parents will be and involved in decision making.

\section{Research on Sexual Education}

a) This study show that effective sexual education can:

i. $\quad$ Reduce misinformation

ii. Increase correct knowledge

iii. Clarify and strengthen positive values and attitudes

iv. Increase skills to make informed decisions and act upon them

v. Improve perceptions about peer groups and social norms

vi. Increase communication with parents, carers or other trusted adults.

b) This research also shows that sharing the above characteristics can help too:

i. Abstain from or delay the debut of sexual relations

ii. Reduce the frequency of unprotected sexual activity

iii. $\quad$ Reduce the number of sexual partners

iv. Increase the use of protection against unintended pregnancy and sexually transmitted infections (STIs) during sexual intercourse.

c) This research also determined family members have been consistently identified adolescent as a significant source of information. This highlights the importance of communication skills, peer pressure, respectful relationships, consent and ethical behaviour in regards to sexual activity. However, communicating clearly enhance positive feelings about sexual activity and feeling confident to negotiate sexual activity and contraception are key indicators of healthy relationships. 


\section{EPRA International Journal of Research and Development (IJRD)}

d)
Despite ongoing concerns of the sexual well-being in adolescent, the vast majority of confident in their decision-making around their sexual health. Dependent for those who are sexually active are, by and large, having sex that they enjoy and feel positive about. The ordinary population those who are not having intercourse are feeling comfortable and confident that this is what they want. This is clearly a strength of adolescent and one which should be recognised in a strength-based approach to sexuality education.

\section{Goal and Target of Intervention}

a) What do adolescent's learn about relationships, sexuality and sexual health.

Sexuality and sexual health relationship taught in an age-appropriate way as part of key learning area. Crossroads extends adolescent learn about many aspects of relationships, sexuality and sexual health. Also embracing learning about body parts and puberty in primary school to rights and responsibilities in sexual relationships, planning and managing sexual health in high school. They learn about the qualities of caring and respectful relationships, recognising abuse and protective strategies. Generally, they also learn about appropriate sources of help and support, including parents, peers and sexual health services. Hence, they're taught to be critical consumers and develop skills in seeking accurate and reliable sources of information, including information from the Internet and media sources. With human sexuality and relationship at its core, formulation young people for the changeover to adulthood has always been one of humanity's great challenges, Today, in a world with AIDS, the way exactly how we meet this confrontation is our most important opportunity in breaking the trajectory of the epidemic."

b) How does best practice comply with, reflect and frameworks?

Counselling therapy are expected one of professional resources to develop adolescent to plan a knowledge and examined in terms of their potential for furthering the best interests focused practice includes:

$\begin{aligned} \text { i. } & \text { Respect } \\ \text { ii. } & \text { Age/ developmentally appropriate responses } \\ \text { iii. } & \text { Realistic expectations } \\ \text { iv. } & \text { Empathy } \\ \text { v. } & \text { Focusing on their needs } \\ \text { vi. } & \text { Ensure they able to participate in decision } \\ & \text { making about his or her future } \\ \text { vii. } & \text { Maintaining appropriate boundaries }\end{aligned}$

viii. Promoting positive experiences and outcomes.

ix. Communicate with family, peers, and teachers about issues that affect health.

x. Make informed and thoughtful decisions about their health.

xi. Take responsibility for themselves and others to improve their health.

xii. Understand and question social norms and practices concerning sexuality, gender and relationships and contribute positively to society.

xiii. Be better equipped to face other challenges in life, especially during the transition period from childhood to adulthood.

xiv. Sexuality education has positive effects, including increasing young people's knowledge and improving their attitudes related to sexual, reproductive health and behaviours.

xv. Sexuality education in or out of schools does not increase sexual activity, sexual risktaking behaviour or STI/HIV infection rates.

xvi. 'Gender-focused' programmes are substantially more effective than 'genderblind' programmes at achieving health outcomes such as reducing rates of unintended pregnancy or STIs.

xvii. Sexuality education has the most impact when school-based programmes are complemented with the involvement of parents, teachers, training institutes and youth-friendly services.

\section{c) The Role of Parents}

Essentially, parents need resources to support their vital role in shaping the lives of adolescents, particularly help in learning effective ways of supporting their adolescent's psychosexual development. It is imperative that this research focus on target evaluations of declining adult's pregnancy rates that can influence positive developmental outcomes. Thus, establish and maintain evaluation goals are deferred because of limited funding whereby research paradigms that can increase knowledge of effective interventions that can be potentially replicated. In this journey community effort to address teenage pregnancy, some parents may be apprehensive about other adults influencing regarding personal, sensitive issues. For parents who feel comfortable and equipped in addressing these issues with their children, including being aware of their own personal values and attitudes regarding sexuality and exactly what way they want their adolescent to be introduced to the sensitive topic of sexuality. Effective parent toward adult communication regarding love and intimacy, as well as family rules and standards about teenage dating, 


\section{EPRA International Journal of Research and Development (IJRD)

can provide needed support for adolescents who are confronting the social and emotional challenges related to puberty. Parents are encouraged to introduce the topic of sexuality and sex education early in an adolescent's development. In what manner the early influenced occurs by the personal values and attitudes of the parents. Hence parent also able to determine as interpreters of the negative media images that foster inconsistent and controversial attitudes toward adolescent in early sexual activity and promiscuity.

Parents are optimistic to become knowledgeable about their adolescent social contexts by monitoring their activities includes not only knowing where they are, but also who are the friends and peer associates of around them. It is also important to provide life options that provided with constructive, safe opportunities for personal growth. Beside other effective models of service include gender-specific interventions that assist adolescents in understanding positive manhood and womanhood development. Throughout the development of positive gender identity, adolescents can fully consider their role in relationships with family, peers, and community. There has been some debate regarding gender-specific versus mixed-gender to address the issue of teenage pregnancy. Giving confidence level to be intentional in their efforts to maximize opportunities for education and life-skills development, optional either in same-gender or mixed-gender environments. Thus, same-gender can provide safe learning environments in which groups can fully consider the challenges facing adolescents to engage in early sexual activity.

Generally, for girls who may have been traumatized by males, it is critical that they have opportunities to voice their concerns and experiences without any perceived threat by male counterparts. On the other hand, in the absence of trauma-related experiences, adolescents may benefit from healthy, mixed-gender awareness that focus on the shared responsibility of both sexes in family planning. Therefore, comprehensive community strategies are needed to address the myriad of issues involved the diversity in social and community contexts. In wide ranging, sexuality education is a curriculum-based process of teaching and learning about the cognitive, emotional, physical and social aspects of sexuality. Perhaps the major discussion that target to equip young people with knowledge, skills, attitudes and values that will empower them to realize their health, dignity, develop respectful, social and sexual relationships. Consider how their choices affect their own well-being and that of others, hence understand to ensure the protection of their rights throughout their lives.

\section{Enhancement Through Therapy}

Adolescent sexuality talks can be a difficult topic for many parents, and once parents have the "birds and the bees" talk, it can be tempting for them to consider the job done. Nevertheless, mostly teens with mental health concerns, keeping an open dialogue is critical to addressing the developmental changes that are inherent in discussions about sexual behaviour. Therapy session can play a key role in encouraging parents to have a series of conversations about sex that can begin when a child is young and continue through their teens. While they may not be the focus of treatment, these conversations can often be a barometer for family communication that can be useful to the therapist. Perhaps therapist can help parents with these discussions by providing the rationale for their importance and giving tips to make these conversations easier for parents, such as the following:

i. Parents should facilitate to recognize that sex is a normal human behaviour and that people begin having sexual feelings at early ages. Coping those feelings, particularly in the absence of adults who will discuss them that can be challenging, create the discussions with parents more valuable. People are assaulted with restrained sexual messages all the time, which can prompt confusion.

ii. Parents should take accountability to identify their message if they are planning a conversation with their teen, help adolescent consider the main idea that they want to get across. The beginning of their journey to aware of their values, or to have information to make safe decisions, or to establish that they are someone their teen can talk to about difficult decisions. Knowing where they are headed with the conversation rather than they begin to making it go smoother.

iii. Practice some key phrases with parents to make sure they feel comfortable with them. Be a great exemplary that they willing to listen and hear that discussing about sex doesn't have to feel embarrassed. Encouraging parents to practice run through when they're alone in the car or in front of the mirror, listening for whether the way they phrased something sounds judgmental or doubting or just plain awkward that able to prepare them well. Hearing themselves say the words is great practice for feeling comfortable, and key phrases that helpful if they are feeling nervous. In fact, if parents are uncomfortable with the terms they might need to use (like "oral sex"), encourage them to practice saying them out loud ahead of time to make it easier.

iv. Reassurance as parents to listen and consider that early teens talk about sex, even if they 


\section{EPRA International Journal of Research and Development (IJRD)

aren't yet sexually active, probably getting "information" from their peers, who may or may not be accurate. Meaning parents who talk about sexuality with their adolescent can correct misconceptions they learn from peers. Perhaps in case parents express that they don't think their teen will come to them with questions or problems, uplift to suggest trust as a source of accurate information for their teen.

v. Inspire parents to communicate their values to teens often interested in what their parents think about things like sex, even if they don't ask directly, and studies show that the more parents discuss their values with their teens the more values converge. Conveying values while recognizing that the point of view they have different life experiences, is important.

vi. Help parents identify naturally occurring moments to start discussions such as scenes in movies, lyrics in music, celebrity scandals reported on $\mathrm{TV}$, or pictures in magazines are great conversation starters. Thus, an opportunity to ask teens an opinion as well as chances for parents to express some of their values.

vii. Remind parents to avoid judgment and coaching teens room to express their opinions that facilitate kind of two-way conversation that is desired. Parents can use facts about risk as a way to express concern rather than judging.

viii. As parents raise the spirits to start early even the best conversations can have limited impact if the timing is wrong. It is assuming most excellent time for parents to talk to teen is before their teen needs the information, not after.

ix. In fact, young people cannot improve sexual and reproductive health alone. They need the support of friends, families, service providers and the wider society. If they meet in groups, they can support each other in positive ways and take actions together to improve things. If they make strong partnerships with others, they can get support to make the community a safer place for everyone.

x. Parents and carers would often like to teach their children more about sexual and reproductive issues but they may need more information themselves, more confidence and approval from the society.

xi. Adults will also learn a lot from the topics and activities in this toolkit. If they learn alongside, it will bring many benefits to both generations in increased knowledge, helpful attitudes and life-skills. This will encourage good relationships and safer sexual behaviour. xii. If parents learn to praise more and criticise less, to be good role-models to their children, to teach with love and to critically think about their changing cultural norms, then they can strengthen the socialisation that they already do.

\section{CONCLUSION}

This research shows that, adolescent youth experience monumental changes in every single aspect of their lives as they make the transition from childhood into adulthood. This study also provides the purpose of the foundational ways for parents and other caregivers needed information to recognize and to appreciate the normal developmental progression of adolescents. Therefore, this article was primarily descriptive in nature. In spite of this process development can become quite challenging and sometimes overwhelming for both youth and their families. In most cases, adolescents explore their sexuality normative and has no negative consequences. Therefore, in this case the compulsive sexual behaviour is developed and needs to be treated or it will affect functioning and relationships in adolescent lifestyle. For this reason, their sexual behaviours have both short-term and long-term consequences, meaning the interventions that focus on multiple domains of risk may be the most effective in helping to promote broad reproductive health among adolescent. Despite the fact that decline in sexual activity is encouraging disheartening that declines among the lowest risk groups, effectively widening the gap of health. Thus, the realistic and factual balanced information about all forms of sexual activity and contraception to adolescents is abundantly clear. Ultimately, a unique position not only provide necessary services to adolescent in a confidential manner, but also to be educators and advocates within their communities about the education and health care needs. Understanding the sexual development of adolescent is utmost importance, unfortunately without this realization no educational intervention movement. The key factors influencing sexuality, understanding is self-indulgent of adolescent sexuality, that enhances help parents to recognize the difficulties of their adolescent lifestyle better and emphasize them to guide crossroads the younger generation. This study also provides parents and other caregiver's concrete advice and practical solutions to common problems that arise during adolescence. Armed with this information, parents will feel more confident and successful as they guide their teen's. 


\section{EPRA International Journal of Research and Development (IJRD)}

\section{REFERENCES}

1. Adelson S, Bell R, Graff A, et al. Toward a definition of "hypersexuality" in children and adolescents. Psychodyn Psychiatry. 2012;40;481-503.

2. Bingham, C.R., \& Crockett, L.J. (1996). Longitudinal adjustment patterns of boys and girls experiencing early, middle, and late sexual intercourse. Developmental Psychology, 32(4), 647.

3. Birchard T. CBT for Compulsive Sexual Behaviour: A Guide for Professionals. New York: Routledge; 2015.

4. Brown JD, L'Engle KL. X-rated: sexual attitudes and behaviors associated with US early adolescents' exposure to sexually explicit media. Comm Res. 2009;36;129-151.

5. CROCKETT, LISA, and CHOPAK, JOANNE S. 1993. "Pregnancy Prevention in Early Adolescence: A Developmental Perspective." In Early Adolescence: Perspectives on Research, Policy, and Intervention, ed. Richard Lerner. Hillsdale, NJ: Erlbaum.

6. Delmonico DL, Griffin EJ. Cybersex addiction and compulsivity. Internet Addiction: A Handbook and Guide to Evaluation and Treatment. New Jersey: John Wiley and Sons, Inc; $\quad 2011 ; 113-134$.

7. DRYFOSS, JOY. 1990. Adolescents at Risk: Prevalence and Prevention. New York: Oxford University Press.

8. Efrati $Y$, Mikulincer $M$. Individual-based Compulsive Sexual Behavior scale: its development and importance in examining compulsive sexual behavior. J Sex Marit Ther. 2018;44;249259.

9. Efrati $Y$, Gola M. Adolescents' compulsive sexual behavior: the role of parental competence, parents' psychopathology, and quality of parentchild communication about sex. J Behav Addic. 2019;8:420-431.

10. Guha $S$ : Attitude, Knowledge and Behavior about Sexuality among Adolescents. IOSR Journal Of Humanities And Social Science 2013, 18(5): 05-19

11. Gruber, E., \& Grube, J. W. (2000). Adolescent sexuality and the media: A review of current knowledge and implications. Western Journal of Medicine, 172, 210-214.

12. Hoffman, Saul D. 1998. "Teenage Childbearing Is Not So Bad After All ... Or Is It? A Review of NewLiterature." FamilyPlanning Perspectives 30 (5):236-239, 243

13. Hallfors, D.D., Waller, M.W., Bauer, D., Ford, C.A., Halpern, C.T. (2005). Which comes first in adolescence-sex and drugs or depression?. American Journal of Preventive Medicine, 29(3), 163-170.

14. Joyner, K, \& Udry, J.R. (2000). You don't bring me anything but down: Adolescent romance and depression. Journal of Health and Social Behavior, 41(4), 369.
15. Kirby , Dougles. 2001. Emerging Answers: Research Findings on Programs to Reduce Teen Pregnancy. Washington, $\quad$ DC: National Campaign to Prevent Teen Pregnancy.

16. Koch, P. B. 1993. "Promoting Healthy Sexual Development During Early Adolescence" In Early Adolescence: Perspectives on Research, Policy, and Intervention, ed. Richard Lerner. Hillsdale, NJ: Erlbaum.

17. Kahn, J.A., Rosenthal, S.L., Succop, P.A., Ho, G.Y., Burk, R.D. (2002). Mediators of the association between age of first sexual intercourseand subsequent human papillomavirus infection. Pediatrics, 109(1), e5e5.

18. Kellett S, Simmonds-Buckley $M$, Totterdell P. Testing the effectiveness of cognitive analytic therapy for hypersexuality disorder: an intensive time series evaluation. J Marit Sex Ther. 2016;6:1-16

19. Mitchell KJ, Wells M. Problematic internet experiences: primary or secondary presenting problems in persons seeking mental health care. Soc Sci Med. 2007;65;1136-1141.

20. Rector, R.E., Johnson, K.A., Noyes, L.R., Martin, $S$. (2003). The harmful effects of early sexual activity and multiple sexual partners among women: a book of charts. Washington: The Heritage Foundation.

21. Ramos VG, Bouris A, Lee J, McCarthy $K$, Michael LS, Barnes PS, Dittus P: Paternal Influences on Adolescent Sexual Risk Behaviors: AStrustured Literature Review. PEDIATRICS 2012, 130(5): e1313-e1325

22. Reissing ED, Giulio GD. Practicing clinical psychologists' provision of sexual health care services. Prof Psychol. 2010;41;57.

23. Reid RC, Bramen JE, Anderson A, Cohen MS. Mindfulness, emotional dysregulation, impulsivity, and stress proneness among hypersexual patients.J Clin Psychol. 2014;70;313- 321.

24. Strasburger VC. Adolescents, sex, and the media: oooo, baby, baby $-a Q \&$ A. Adolesc Med Clin 2005; 16: 269-288.

25. Sabia, J.J., \& Rees, D.I. (2008). The effect of adolescent virginity status on psychological wellbeing. Journal of Health Economics, 27(5), 1368-1381.

26. Sandfort, T.G., Orr, M., Hirsch, J.S., Santelli, J. (2008). Long-term health correlates of timing of sexual debut: results from a national US study. American journal of public health, 98(1), 155-161.

27. Yip SFP, Zhang H, Lam TH, Lam KF, Lee AM, Chan J, Fan S: Sex Knowledge, attitudes, and high risk sexual behaviors among unmarried youth in Hongkong 2013, 13(691): 1-10 